\title{
Shear Bond Strength of Repaired Ceramic-Metal Restorations Using Different Bonding Agents with Different Surface Treatments
}

\author{
Ibrahim M. Hamouda ${ }^{1,2 *}$, Enas M. Elddainony ${ }^{3}$, Mosaad A. ELgabrouny ${ }^{3}$, Fahim M. El-Shamy ${ }^{2}$ \\ ${ }^{1}$ Professor of Dental Biomaterials, College of Dentistry, Umm Alqura University, Makkah, KSA. \\ ${ }^{2}$ Professor of Dental Biomaterials, Faculty of Dentistry, Mansoura University, Mansoura, Egypt. \\ ${ }^{3}$ Assistant professor, Faculty of Dentistry, Suez Canal University, Egypt.
}

*Corresponding Author: Ibrahim M. Hamouda, 1Professor of Dental Biomaterials, College of Dentistry, Umm Alqura University, Makkah, KSA.

\section{Received Date: 10 August 2021 | Accepted Date: 26 October 2021 | Published Date: 02 November 2021}

Citation: Ibrahim M Hamouda, Enas M Elddainony, Mosaad A ELgabrouny, Fahim M El-Shamy. (2021). Shear Bond Strength of Repaired Ceramic-Metal Restorations Using Different Bonding Agents with Different Surface Treatments. International Journal of Clinical Case Reports and Reviews. 9(1); DOI:10.31579/2690-4861/162

Copyright: () 2021 Ibrahim M. Hamouda, This is an open-access article distributed under the terms of the Creative Commons Attribution License, which permits unrestricted use, distribution, and reproduction in any medium, provided the original author and source are credited.

\begin{abstract}
Background: Fracture of ceramic-metal restorations is a major problem facing the dentists and the patients. There are several bonding systems currently available in the market to repair the fractured ceramic-metal restorations inside or outside the oral cavity.

Purpose: The purpose of this study was to test the efficiency of repairing of metal-ceramic restorations using different bonding systems with different surface treatments. This efficiency was tested through the conduction of shear bond strength of the composite bonded to the porcelain and to nickel-chromium alloy using three different bonding agents (Excite, AdheSE, and Prompt L-Pop) with four different surface treatments (sandblasting and enchant, diamond stone roughening, sandblasting and hydrofluoric acid etching, or without surface treatment).
\end{abstract}

Materials and Methods: A total of 120 specimens were prepared, 60 specimens from porcelain and 60 specimens from nickel-chromium alloy. Each group was divided into three equal subgroups, 20 specimens each, corresponding to the 3 bonding agents used. Each subgroup was further subdivided into four subgroups, 5 specimens each, corresponding to the surface treatment procedures. Bonding agents applied over all specimens and cured, followed by application of a microhybrid light-cured composite resin (Tetric Ceram). Thermal cycling was done for all specimens between $5^{\circ} \mathrm{C}$ and $55^{\circ} \mathrm{C}$ for 1000 cycles with a 10-second dwell time. Shear bond strength test was conducted using a universal testing machine at a cross-head speed of $0.5 \mathrm{~mm} / \mathrm{min}$.

Results: The highest shear bond strength value recorded for the porcelain specimens bonded with Excite bonding agent with surface treatment sandblasting and hydrofluoric acid etching. In metal groups, the AdheSE bonding agent showed the highest shear bond strength value with the same surface treatment of the porcelain specimens. It was observed that sandblasting followed by hydrofluoric acid etching produced the most effective treatment method for porcelain and metal surfaces.

Conclusion: The most effective technique for repairing metal ceramic restoration was sandblasting with hydrofluoric acid etching as surface treatment together with AdheSE or Excite bonding agents.

Keywords: ceramo-metallic restorations; sandblasting; hydrofluoric acid etching; bonding agents

\section{Introduction}

Ceramic was first introduced to the dentistry for making denture teeth by De Chemant in 17th century and followed by Alex Duchateau [1]. Ceramic-metal restorations are widely used in dentistry because of excellent esthetic qualities and biocompatibility. Fracture in ceramic- metal restorations can occur and could be repaired because its replacements are not an economic solution [2]. A perfect repair of the fractured metal-ceramic restorations are the best solution in most of cases. There are two types of bonds, metal-resin bond and porcelain-resin bond, which involved in the repair process of ceramic-metal restorations. Surface configuration, reactivity of the bonding surfaces, and use of 
adhesive resins are important for metal-resin bond [3].

Fracture of metal-ceramic restorations in the form of chipping or de-veneering of ceramic due to bond failure between ceramic and metal. Fracture may result from trauma, fatigue, occlusal prematurity, parafunctional habits, poor abutment preparation, inappropriate coping design and incompatibility of coefficient of thermal expansion between ceramic and the metal structure $[1,4]$. Intraoral chair side porcelain repair systems are a quick, painless and highly patient acceptable techniques, and no need for removal of restorations or fabrication of a new restorations [4].

Various techniques for repair have been used as an alternative to the expensive and time-consuming procedure of remaking prostheses. Repairing methods have been classified into, indirect methods and direct methods. Indirect repair would mean repair of the prosthesis in the laboratory using ceramic as a repair material. It is advantageous due to the esthetic ability of porcelain to match the remaining ceramic units. The drawbacks of this procedure were increased time and cost. Moreover, during removal of the prosthesis fracture of abutment tooth or porcelain veneer may occur [5].

The direct technique uses composite for intraoral repair of the fractured porcelain. A number of systems have been developed to facilitate bonding of composite to porcelain and metal [6].The techniques included surface preparation of ceramics and silane treatment for bonding procedure [7].The surface treatment of porcelain and metal includes diamond roughening, air particle abrasion with metal oxide and etching with acids [8]. Surface treatments help in micromechanical retention. The formation of reliable and durable chemical bonds between dental ceramics and composite resins is of paramount importance, which is due to the invention of silane coupling agents. These agents chemically bond dissimilar organic and inorganic compounds together and help in chemical retention [7].The advantages of using composites are less chairside time, low cost and ease of application, whereas disadvantages include low strength, poor wear resistance, and poor esthetic qualities [5].

Recently, physical alteration of ceramic and metal substrates together with chemical agents such as metal primer, ceramic primer and

\begin{tabular}{|c|c|c|c|c|}
\hline Group & Subgroups & Surface treatments & Etching & Adhesive \\
\hline A & A1 & Sandblasting & Phosphoric acid & Excite \\
\hline & A2 & Roughness with stone & Hydrofluoric acid & \\
\hline & A3 & Sandblasting & Phosphoric acid & \\
\hline & A4 & No treatment & Phosphoric acid & AdheSE \\
\hline B & B1 & Sandblasting & AdheSE primer & bond \\
\hline & B2 & Roughness with stone & AdheSE primer & Prompt L-Pop \\
\hline & B3 & Sandblasting & Hydrofluoric acid & \\
\hline C & B & No treatment & AdheSE primer & \\
\hline & C1 & Sandblasted & All-in-one self-etch & \\
\hline & C 2 & Roughness with stone & All-in-one self-etch & \\
\hline
\end{tabular}

Table I: Shows the tested porcelain groups

\section{A. Using Excite bonding agent with porcelain specimens}

\section{Subgroup A1:}

5 Specimens were sandblasted vertically using $\mathrm{Al}_{2} \mathrm{O}_{3}$ particles with average particle size 100um, at a pressure of 1.5 bars, for $10 \mathrm{~s}$ from a distance of $2 \mathrm{~cm}$ [11]. Specimens were etched using phosphoric acid (total etch) for $30 \mathrm{~s}$, etchant rinsed with water spray for $20 \mathrm{~s}$, then air dried. A silane coupling agent applied (Ultrdent ${ }^{\circledR}$ Silane, Ultrdent Products, South Jordan, UT) [12]. Using a small brush, a layer of Excite applied to the etched surfaces and dried using a gentle air for $2 \mathrm{~s}$ at $5 \mathrm{~mm}$ distance, then improved silane coupling agents to promote adhesion of resin to fractured metal-ceramic restorations were introduced $[9,10]$. Since the reported shear bond strengths in the literatures for repairing metal-ceramic restorations are different, this study conducted to detect which bonding agent and surface treatment more effective in repairing of fractured metaceramic restorations.

\section{Material and Methods}

The materials used in this study were: (1) Excite, $5^{\text {th }}$ generation bonding agent ( Ivoclar Vivadent, Liechtenstein, Germany), (2) AdheSE, $6^{\text {th }}$ generation bonding agent (Ivoclar Vivadent, Liechtenstein, Germany), (3) Prompt L-Pop $7^{\text {th }}$ generation bonding agent $(3 \mathrm{M}$ Dental Products, St. Paul, MN, USA), (4)Tetric-Ceram, Microhybride composite resin (( Ivoclar Vivadent, Liechtenstein, Germany), (5) Vita metal ceramics, Feldspatheic Dental Porcelain ( VitA Zahnfabrik, Spitalglasse 3, D-79713 Bad Sackingen,Germany), and (6) Wiron Light Ni-Cr alloy, metalceramic alloy ( Bego, Wilhelm-Herbst, Germany). A total of 120 specimens were prepared, 60 from porcelain, and 60 from nickelchromium alloy.

\section{Preparation of porcelain specimens}

A total of 60 specimens prepared using a specially designed Teflon mold of $7 \mathrm{~mm}$ diameter and $2 \mathrm{~mm}$ thickness. Porcelain powder mixed with the liquid according to the manufacturer's instructions. Porcelain mix placed into the mold in layers, vibrated and the excess liquid was blotted away. The condensed porcelain specimens fired according to the manufacturer's instructions in calibrated furnace (Lectra, Ugin, France). Porcelain specimens were ready for composite resin bonding.

\section{Composite-porcelain bonding}

60 porcelain specimens were embedded in a polyvinyl chloride rings $2 \mathrm{~cm}$ dimeter and $2 \mathrm{~cm}$ height using polymethyl methacrylate resin. Specimens divided into 3 groups (A, B, C), 20 specimens each, corresponding to the used bonding agents, then subdivided into 4 subgroups (A1, A2, A3, and $\mathrm{A} 4),(\mathrm{B} 1, \mathrm{~B} 2, \mathrm{~B} 3$, and B4), and (C1, C2, C3, and C4) corresponding to the surface treatment techniques, 5 specimens each Table I. 
5 Specimens were surface treated by roughness with a water cooled diamond stone (Electroplated HP Diamonds, DFS Diamon Gmblt, Riedenburg, Germany). Roughness done for $15 \mathrm{~s}$, rinsed in water, dried, etched and silinated. A layer of Excite was applied to the porcelain specimen's surfaces and cured. Composite resin built and cured as subgroup A1.

\section{Subgroup A3:}

5 Specimens were surface treated by sandblasting and etching with $9 \%$ hydrofluoric acid (Porcelain etch, Ultrdent Products; South Jordan, UT). Etchant rinsed for $10 \mathrm{~s}$, air dried, Excite bonding agent applied and composite resin was built up.

\section{Subgroup A4}

5 Specimens were etched only with phosphoric acid as subgroup A1 without any surface treatments. Excite bonding agent applied, composite resin was built up and both were cured.

\section{B. Using AdheSE bonding agent with porcelain specimens}

20 porcelain specimens classified (B1, B2, B3, B4), treated and built up in composite resin as mentioned in group A except using of AdheSE bonding agent instead of Excite. AdheSE primer was applied to the porcelain specimens with brush for $30 \mathrm{~s}$, excess material removed using strong stream of dry air. AdheSE Bond applied with a small brush and dried with weak stream of dry air and light cured for $20 \mathrm{~s}$.

\section{Using Prompt L-Pop bonding agent with porcelain specimens}

20 porcelain specimens were classified $(\mathrm{C} 1, \mathrm{C} 2, \mathrm{C} 3, \mathrm{C} 4)$, treated and built up in composite resin as mentioned in group A except using of Prompt LPop (All-in-one self-etch adhesive) bonding agent instead of Excite. Prompt L-Pop applied to the porcelain specimens according to the

manufacturers instructions for $15 \mathrm{~s}$, dried with dry air and light cured for $20 \mathrm{~s}$ followed by the composite resin built up.

\section{Preparation of metal specimens}

A total of 60 specimens prepared using the previous Teflon mold from blue inlay casting wax (Crown Wax, Bego, Germany) in incremental layers. Wax sprues attached to the prepared wax patterns using sticky wax. Wax specimens invested in phosphate-bonded investment (Bella Vest SH, Bego, Germany). Wax elimination done in an oven by rising the temperature gradually to $3000 \mathrm{C}$ in $3 \mathrm{o} \mathrm{min}$, then raised up to $8500 \mathrm{C}$ for 1 h. Casting done in $\mathrm{Ni}-\mathrm{Cr}$ alloy using centrifugal casting machine (Ducatron Series 3, Ugin Dentaire, Seyssins, France).

Specimens divested after slow cooling to room temperature, cleaned by air borne-particles abrasion, using $50 \mathrm{~mm}$ aluminum oxide powder (Williams Blasting Compound, Ivoclar, Vivadent, Amherst, NY) at 4 bar pressure. Specimens were ultrasonically cleaned in distilled water for 10 min. Metal specimens were ready for composite resin bonding. Specimens of nickel- chromium alloy classified into three groups (D, E, F), 20 specimens each, corresponding to three bonding agents. Each group was classified into 4 subgroups (D1,D2,D3,D4); (E1,E2,E3,E4); and (F1,F2,F3,F4), 5 specimens each, corresponding to 4 surface treatment techniques.

\section{Composite-metal bonding}

The prepared metal specimens classified (Table II), surface treated, bonding agents were applied and composite resin built up as mentioned above in the porcelain specimens except the application of opaquer. Opaque resin (Monopaque, Ivoclar-Vivadent, Liechtenstein, and Germany) applied to the metal specimens and light cured for $20 \mathrm{~s}$ before composite built up [13]. All specimens stored again in distilled water after thermal cycling for additional 24 hours at $370 \mathrm{C}$ before shear strength testing [14].

\begin{tabular}{|c|c|c|c|c|}
\hline Group & Subgroups & Surface treatments & Etching & Adhesive \\
\hline D & D1 & Sandblasting & Phosphoric acid & Excite \\
\hline & D2 & Roughness with stone & Hydrofluoric acid & \\
\hline & D3 & Sandblasting & Phosphoric acid & Phosphoric acid \\
\hline E & D4 & No treatment & AdheSE primer & AdheSE \\
\hline & E2 & Sandblasting & AdheSE primer & bond \\
\hline & E3 & Sandblasting & Hydrofluoric acid & Prompt L-Pop \\
\hline & E4 & No treatment & All-in-one self-etch & \\
\hline F & F1 & Sandblasted & All-in-one self-etch & \\
\hline & F2 & Roughness with stone & Hydrofluoric acid & \\
\hline & F3 & Sandblasting & All-in-one self-etch & \\
\hline
\end{tabular}

Table II: Shows the tested $\mathrm{Ni}$-Cr groups

\section{Shear bond strength testing}

Each specimen was mounted in a computer-controlled testing machine (Model LRX- plus; Lloyd Instruments Ltd., Fareharn, UK) with a load cell of $5 \mathrm{KN}$. Data recorded using computer software (Nexygen MT; Lloyd Instruments). Specimen secured to the lower fixed compartment of the testing machine by tightening screws. Shearing test done by compressive load applied at composite-substrate interface using a monobeveled chisel shaped metallic rod attached to the upper movable compartment of the testing machine at cross-head speed of $0.5 \mathrm{~mm} / \mathrm{min}$. The load of debonding recorded in Newton and divided by the bonding area to express the bond strength in $\mathrm{MPa}[1,2]$ :

$$
6=\mathrm{P} / \mathrm{xr} 2
$$

Where; $6=$ shear bond strength $(\mathrm{MPa})$, $\mathrm{P}=$ loadat failure $(\mathrm{N})$, $\mathrm{x}=3.14$, and $\mathrm{r}=$ radius of composite disc $(\mathrm{min})$.

\section{Statistical analysis:}

Data collected, analyzed and compared using 2-way analysis of variance (ANOVA) statistical test at $95 \%$ confidence level. The Least significant difference (LSD) statistical test used to determine the significant difference between groups and subgroups.

\section{Results}

The results of shear bond strength of the repaired composite resin to the porcelain specimens are presented in Table III. Sandblasting and hydrofluoric acid etching together with Excite bonding agent application to porcelain specimens showed the highest shear bond strength. On the other hand, surface roughness together with AdheSE bonding agent applied to porcelain specimens showed the lowest shear bond strength. 
The statistical analysis of the results showed significant differences between the different surface treatments and different bonding agents of the repaired porcelain specimens (Table IV).

\begin{tabular}{|c|c|c|c|}
\hline Surface treatments & $\begin{array}{c}\text { Excite } \dot{X} \pm \\
\text { SD }\end{array}$ & $\begin{array}{c}\text { Bonding agents } \\
\text { AdheSE } \dot{X} \pm \text { SD }\end{array}$ & $\begin{array}{c}\text { Prompt L-Pop } \\
\hat{X} \pm \text { SD }\end{array}$ \\
\hline $\begin{array}{c}\text { Sandblasting and } \\
\text { phosphoric acid etching }\end{array}$ & $6.26 \pm 1.9$ & $5.17 \pm 1.4$ & $8.98 \pm 0.9$ \\
\hline Roughness with stone & $4.56 \pm 0.8$ & $2.59 \pm 0.4$ & $2.79 \pm 0.7$ \\
\hline $\begin{array}{c}\text { Sandblasting and } \\
\text { hydrofluoric acid etching }\end{array}$ & $14.02 \pm 2.8$ & $11.91 \pm 1.2$ & $11.95 \pm 2.0$ \\
\hline No treatment & $8.36 \pm 1.6$ & $5.311 \pm 1.4$ & $7.56 \pm 1.0$ \\
\hline P-value & & $\leq 0.001^{*}$ & \\
\hline
\end{tabular}

* The mean difference is significant at the 0.05 level.

Table III: Shows mean shear bond strength (MPa) of composite resin to porcelain.

\begin{tabular}{|c|c|c|c|c|c|}
\hline $\begin{array}{c}\text { Source of } \\
\text { variance }\end{array}$ & Sum of Square & df & $\begin{array}{c}\text { Mean } \\
\text { Squares }\end{array}$ & F & P-value \\
\hline Bonding agents & 46.93 & 2 & 23.46 & 6.17 & 0.004 \\
\hline $\begin{array}{c}\text { Surface } \\
\text { treatments }\end{array}$ & 708.1 & 3 & 236.1 & 62.0 & 0.0001 \\
\hline Interactions & 10.42 & 6 & 1.736 & 0.46 & 0.836 \\
\hline
\end{tabular}

Table IV: ANOVA test results for composite-porcelain bonding.

Table $\mathrm{V}$ shows the shear bond strength of the repaired Ni-Cr alloy specimens with composite resin. Sandblasting and hydrofluoric acid etching together with AdheSE bonding agent applied to $\mathrm{Ni}-\mathrm{Cr}$ alloy specimens showed the highest shear bond strength. On the other hand, surface roughness together with Prompt L-Pop bonding agent applied to $\mathrm{Ni}-\mathrm{Cr}$ alloy specimens showed the lowest shear bond strength. The

Showed the lowest shear bond strength. The
\begin{tabular}{|c|c|c|c|}
\hline Surface treatments & Excite $\dot{X} \pm$ SD & $\begin{array}{c}\text { Bonding agents } \\
\text { AdheSE } \tilde{X} \pm \text { SD }\end{array}$ & $\begin{array}{c}\text { Prompt L-Pop X́ } \\
\pm \text { SD }\end{array}$ \\
\hline $\begin{array}{c}\text { Sandblasting and } \\
\text { phosphoric acid etching }\end{array}$ & $10.86 \pm 1.6$ & $9.42 \pm 1.4$ & $4.67 \pm 0.9$ \\
\hline Roughness with stone & $7.15 \pm 1.5$ & $12.2 \pm 2.0$ & $2.04 \pm 0.5$ \\
\hline $\begin{array}{c}\text { Sandblasting and } \\
\text { hydrofluoric acid etching }\end{array}$ & $6.58 \pm 1.4$ & $15.65 \pm 2.1$ & $6.34 \pm 1.2$ \\
\hline No treatment & $6.74 \pm 1.6$ & $15.38 \pm 2.5$ & $4.4625 \pm 0,4$ \\
\hline P-value & & $\leq 0.001^{*}$ & \\
\hline
\end{tabular}

* The mean difference is significant at the 0.05 level.

Table V: Shows mean shear bond strength $(\mathrm{MPa})$ of composite resin to metal $\mathrm{Ni}$-Cr alloy.

\begin{tabular}{|c|c|c|c|c|c|}
\hline $\begin{array}{c}\text { Source of } \\
\text { variance }\end{array}$ & $\begin{array}{c}\text { Sum of } \\
\text { Square }\end{array}$ & df & $\begin{array}{c}\text { Mean } \\
\text { Squares }\end{array}$ & F & P-value \\
\hline Bonding agents & 46.93 & 2 & 324.6 & 38.08 & 0.0001 \\
\hline $\begin{array}{c}\text { Surface } \\
\text { treatments }\end{array}$ & 42.06 & 3 & 14.02 & 1.68 & 0.183 \\
\hline Interactions & 161.3 & 6 & 26.88 & 3.22 & 0.009 \\
\hline
\end{tabular}

Table VI: ANOVA test results for composite-metal bonding.

SEM analysis of composite-porcelain repaired specimens revealed different types of failures. Excite bonding agent had, 8 specimens cohesive failure (Fig. 1), 6 specimens adhesive failure, and 6 specimens mixed failure. AdheSE bonding agent had, 5 specimen's cohesive failure, 11 specimens' adhesive failure (Fig.2), and 4 specimens mixed failure. Prompt L-Pop bonding agent had, 5 specimen's cohesive failure (Fig.3), 10 specimens adhesive failure, and 5 specimens mixed failure. statistical analysis of the results showed significant differences between the different bonding agents of the repaired Ni-Cr alloy specimens (Table VI). On the other hand, there were no significant differences between the different surface treatments of the repaired $\mathrm{Ni}-\mathrm{Cr}$ alloy specimens $(\mathrm{P} \geq 0.05)$. 


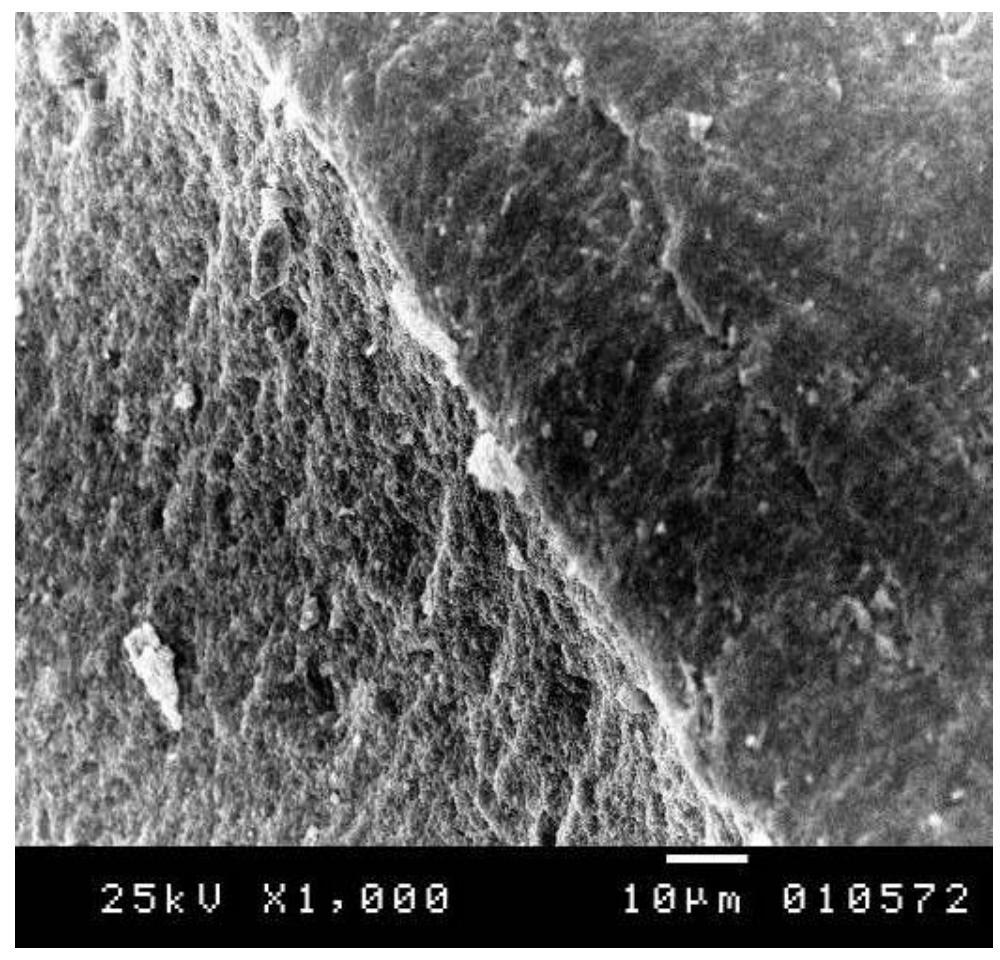

Figure 1: The SEM photomicrograph showing cohesive failure in composite resin

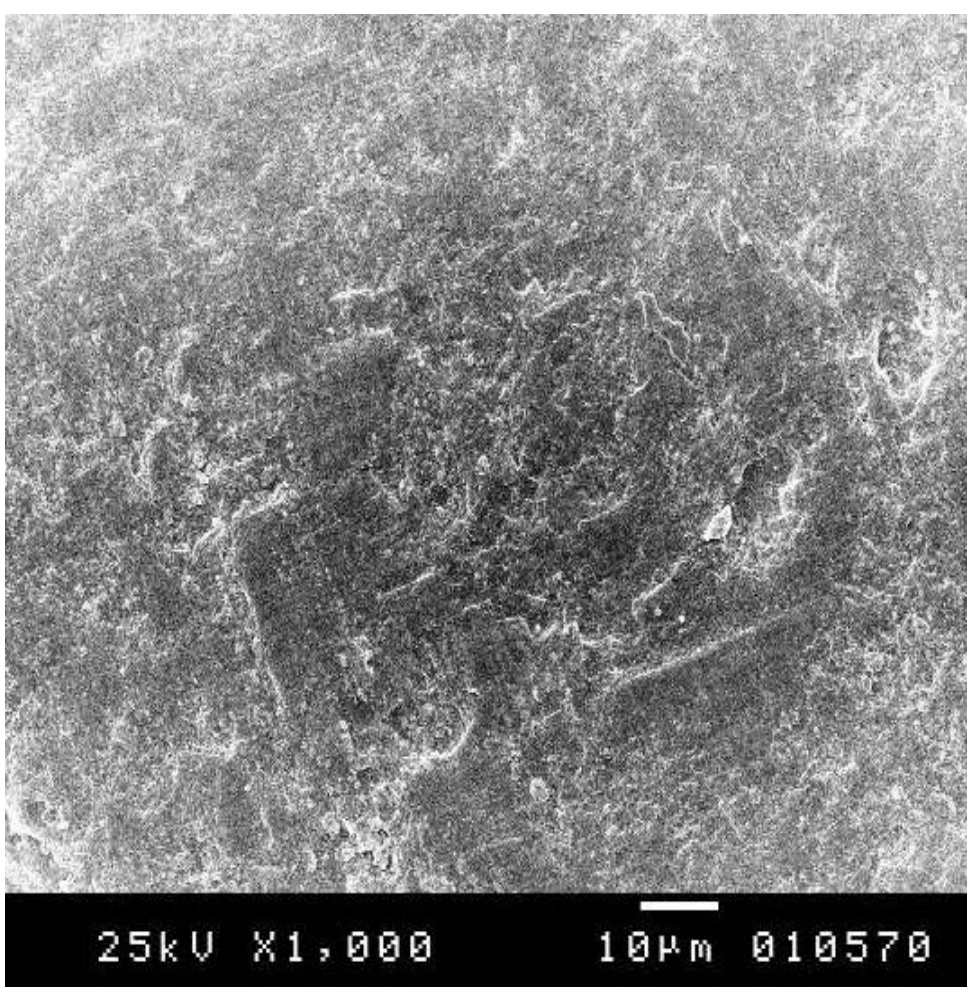

Figure 2: The SEM photomicrograph showing adhesive failure between porcelain substrate and composite resin 


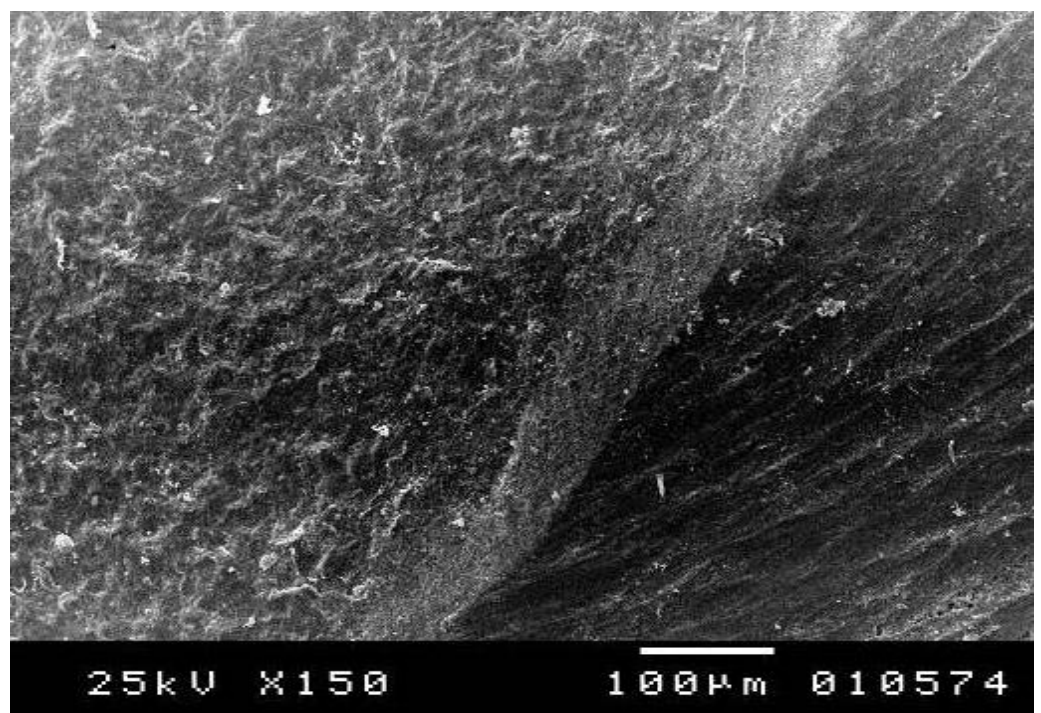

Figure 3: The SEM photomicrograph showing cohesive failure in porcelain substrate

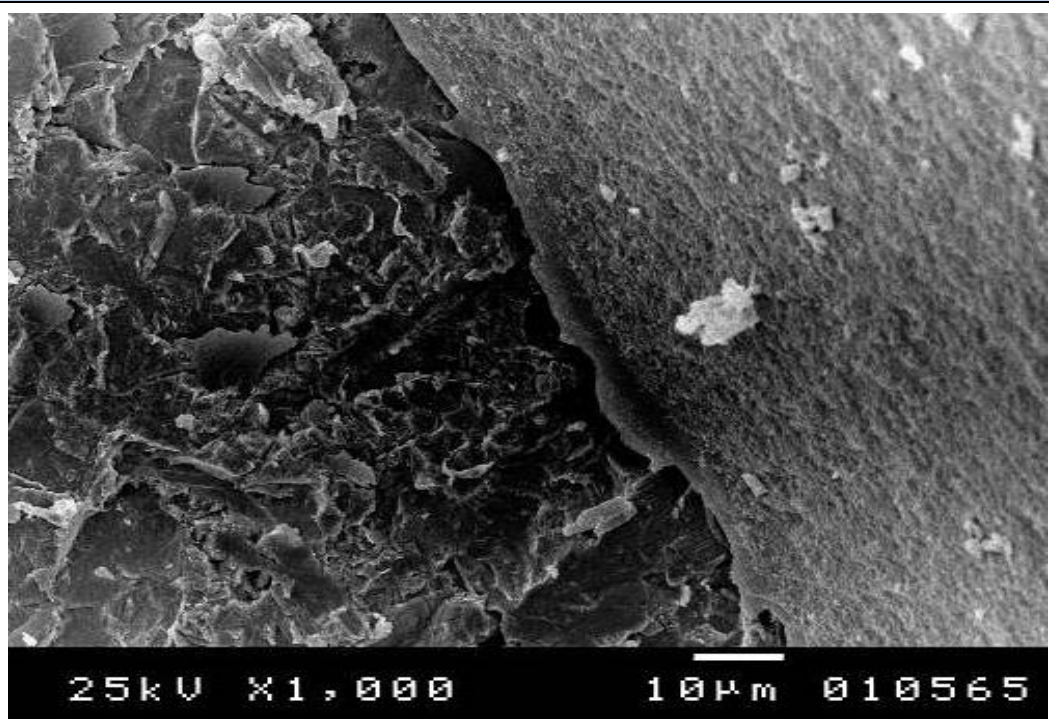

Figure 4: The SEM photomicrograph showing mixed adhesive-cohesive failure between metal substrate and composite resin

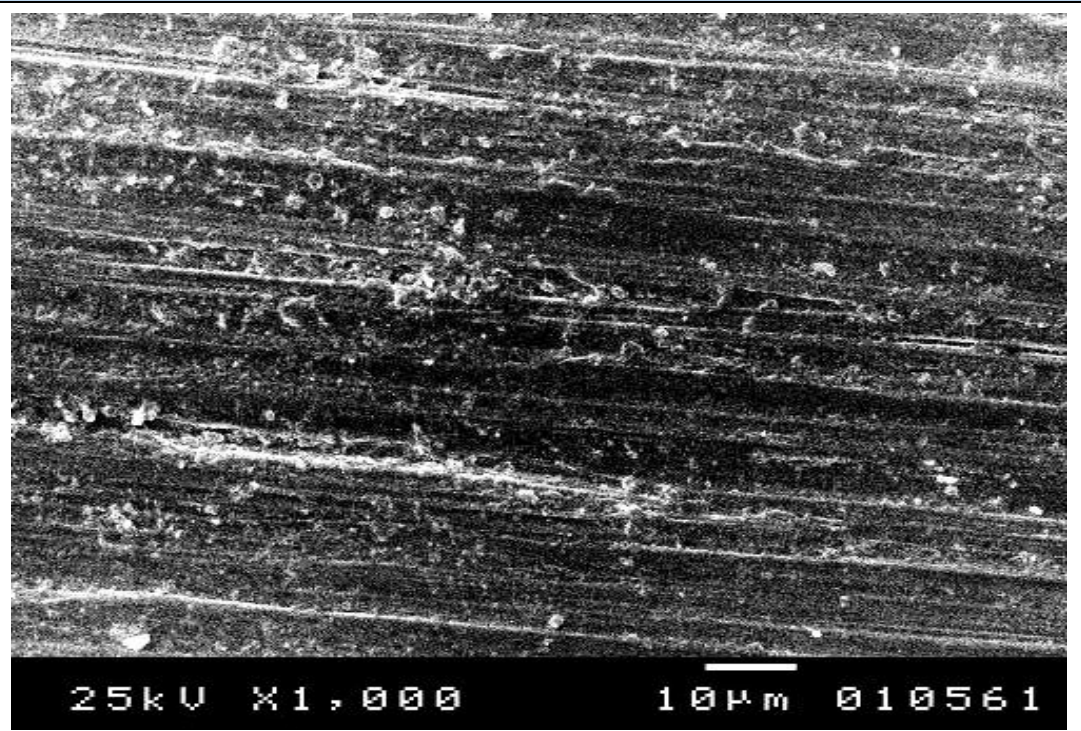

Figure 5: The SEM photomicrograph showing adhesive failure between metal substrate and composite resin 


\section{Discussion}

Metal-ceramic restorations are common in dentistry for restoration of teeth. It was stated in the literatures that anterior metal-ceramic restorations are subjected for fracture [6]. Anterior restorations are subjected to shear stresses, and the shear bond test is considered appropriate for predicting the strength of the intraoral porcelain repairs [15]. Although porcelains or ceramics have been used commonly in dentistry, it has several disadvantages. Feldspathic porcelain has compressive strength more less than enamel [7]. So, this porcelain has the ability to fracture due to several reasons such as impact load, occlusal forces, incompatible coefficient of thermal expansion between porcelain and metal substructures, use of metal with low elastic modulus, improper design, excessive seating force during trial insertion or cementation, micro-defects within the material and trauma [4].

The adhesive interfaces between porcelain and metal substructures could be subjected to thermal changes, $\mathrm{pH}$ changes, saliva, and fatigue that can destroy the ceramic-metal bond which have low tensile strength. Therefore, failures in porcelain restorations are more common [7]. Failures of metal-ceramic restorations could be classified into simple (involving the porcelain body only), mixed (involving the porcelain associated with exposure of metal) and complex (with substantial metal exposure) $[5,7]$.

Intraoral repair system enhances the mechanical and chemical bonds between resin and metal or ceramic substrate by increasing the surface area, decreasing the surface tension and causes physical changes which promote adhesion of resin materials to porous surfaces of the metal-ceramic restorations. The physical changes are achieved by selective chemical dissolving the glassy matrix of the ceramic material [16-18].

The suitable repair technique depends on the cause of fracture. Intraoral and extra oral porcelain repairs are two possible ways of repair techniques. Intraoral technique with direct application of composite resin is a common and more practical treatment for fractured metal-ceramic restorations. The direct intraoral repair technique requires fewer skills, less time-consuming, less costly, less destructive, and more convenient for the patient and dentist [19].

However, the intra-oral repairing technique is associated with several drawbacks. The most common drawback is de-bonding of composite resin material from the fractured metal-ceramic restoration after short time in service. The bond of intraoral repair system depends on mechanical and chemical factors. The chemical factors can be achieved by silanization while mechanical retention can be achieved by surface roughness. The later include macro-mechanical and micromechanical methods [19, 20]. Macro-mechanical retention can be achieved by sandblasting the fractured surface with aluminum oxide particles, grinding with stone burs or silicon carbide paper [21]. These techniques for repair metal-ceramic restorations create a micro-retentive surface and increase the roughened surface area for bonding and thus its wettability [17]. The results of this study showed increased shear bond strength with sandblasting and application of hydrofluoric acid for etching of porcelain as surface treatment. On the other hand, the type of the adhesive play principle role in improving the shear bond strength of $\mathrm{Ni}-\mathrm{Cr}$ alloy.

This study used three bonding agents and four types of surface treatments included mainly mechanical means of retention. Micromechanical retention could be produced for repairing of metal ceramic restorations by itching the surfaces with hydrofluoric, phosphoric or acidulated phosphate fluoride acids $[17,20]$. In a conflict of our research, a study concluded that, the roughness with burs as a surface treatment was the technique of choice for roughening fractured porcelain surfaces. Bur roughness with phosphoric acid etching was the technique of choice for roughening metal exposed surfaces (Metal) and burhydrofluoric treatment is the technique of choice for roughening metalporcelain combined surfaces (Metal-Porcelain) [22].

Various repairing techniques such as acid etching, sandblasting, silanization, and application of metal primer have been introduced for repairing of fractured metal-ceramic restorations. Acid etching of feldspathic porcelain provides micromechanical undercuts that have the main effect for better adhesion [23]. Several researches have reported that a combination of micromechanical roughness and silane application technique to the porcelain creates long lasting bonding \{24]. This study showed that the higher shear bond strength recorded for repaired porcelain with composite resin when sandblasting and hydrofluoric acid used as a surface treatment with all bonding agents. On the other hand, the lowest shear bond strength recoded for porcelain specimens roughened with dental stone burs only with all bonding agents.

The maximum bond between the repaired surfaces, there are various methods of providing mechanical and chemical bonding could be used. Mechanical means of retentions could be gained by air abrasion with aluminum oxide particles which results in clearing superficial contaminations, increasing the wettability of the surface by resins, increasing the surface roughness, and improving the bond between the composite and substructures [19]. Etching the surface with acids such as hydrofluoric acid leads to dissolution of glass matrix of ceramics and develop a porous surface for god bond of the composite resin in these pores $[1,19]$.

Application of mechanical and chemical surface treatments techniques could lead to an increased bond strength of the composite to the material surface, depending on the type of material substrate. Surface treatment using diamond burs can cause increased abrasion of the alloy surface and development of fixed points for increasing the surface roughness [25]. This study indicated that, there was no significant difference between four studied surface treatments for roughness of $\mathrm{Ni}$ $\mathrm{Cr}$ alloy for bonding with composite resin one of them was the roughness with diamond stone. While there was a significant difference between three tested bonding agents. Air abrasion using aluminum oxide particles coated with silica, pressure is exerted to the surface together with surface roughness, the remaining silica on that metal surface leads to improved silane function in the composite resin bonding [26].

Silane coupling agent used able to form a chemical bond between the organic (composite resin) and inorganic (porcelain) structures, and its application together with the silica layer remaining on the surface caused increased bond strength of the composite particularly to the ceramic surface $[19,26]$. A research tested the strength of the shear bond for aged composite to ceramic-base metal alloy specimens with application of air abrasion, surface etching with hydrofluoric acid plus using of phosphate monomer compounds and silane resulted in higher composite bond strength to the surfaces [25]. Also, this study indicated that sandblasting and etching with hydrofluoric acid was the more appropriate surface treatment technique for repairing metal-ceramic restorations.

In the meta-analysis of substrate metal-ceramic samples without aging, application of air abrasion leads to a significant increase in the bond strength of composite resin when using chemical compounds of the group without the mentioned functional monomers [27]. A study concluded that, the shear bond strength of a ceramic repair with $40 \%$ phosphoric acid etching showed highest bond strength when compared to other systems and surface treatments [4]. Another researchers concluded that the exposed metal surface of fractured metal ceramic restorations treated with sandblasting or sandblasting and etching the surrounding ceramic surface with hydrofluoric acid increased the shear bond strength of the repaired metal ceramic area. Porcelain repair systems which contain hybrid composites and 4-META as primer had increased bond strength 
[28].

A research showed combinations of mechanical and chemical treatment techniques improved the shear bond strength between intraoral repair materials and the surface of fracture metal-ceramic restorations. Air abrasion with 50 um aluminum oxide increased the shear bond strength for both ceramic and metal substrate when repaired with three different intraoral repair systems [25]. Another study concluded that air abrasion with 50 um aluminum oxide particles is more effective then roughening with diamond bur for improving the shear bond strength of all the intraoral repair system to both metal and ceramic [29].

SEM study of this research showed most of repaired porcelain specimens exhibited adhesive failure between composite resin and porcelain. On the other hand, most of the repaired $\mathrm{Ni}-\mathrm{Cr}$ alloy specimens exhibited mixed failure. Cohesive fractures are more favorable and more easier to repair when compared to adhesive fracture. Clearfil repair kit is the material of choice for cohesive fracture when compared to $\mathrm{P}$ and $\mathrm{R}$ Shofu repair kit, while $\mathrm{P}$ and $\mathrm{R}$ repair kit is the material of choice for adhesive fracture when compared to Clearfil repair kit [30].

\section{Conclusions}

Excite bonding agent had the highest shear bond strength for porcelain repairing with composite resin. On the other hand, AdheSE bonding agent had the highest shear bond strength for bonding of composite resin to Ni-Cr alloy. Sandblasting followed by hydrofluoric acid etching showed the most effective method for treating the surface of both porcelain and $\mathrm{Ni}-\mathrm{Cr}$ alloy. Most of repaired porcelain specimens exhibited adhesive failure between composite resin and porcelain, while most of the repaired $\mathrm{Ni}-\mathrm{Cr}$ alloy specimens exhibited mixed failure.

\section{References}

1. Anusavice JK. (2003). Phillips Science of Dental Materials. 11ed. St Louis. Elsevier.210-240.

2. Tulunoglu IF, Beydemir B. (2000). Resin shear bond strength to porcelain and a base metal alloy using two polymerization schemes. J Prosthet Dent. 83:181-186.

3. Cooley RL, Tseng EY, Evans JG. (1991). Evaluation of 4META porcelain repair system. J Esther Dent. 3:11-13.

4. Kalra A, Mohan MS, Gowda EM. (2015). Comparison of shear bond strength of two porcelain repair systems after different surface treatment. Contemporary Clinical Dentistry. 6(2): 196200.

5. Latta MA, Barkmeier WW. (2000). Approaches for intraoral repair of ceramic restorations. Compend Contin Educ Dent. 21:635 639 .

6. Ozcan M. (2003). Fracture reasons in ceramic fused to metal restorations. J Oral Rehabil. 30:265 269.

7. Moaleem MM, Ahmari NM, Dosari MK, Abdulla HA. (2013). Repairing of fractured metal ceramic restorations techniques review. Int J Contemp Dent. 4:21 30.

8. Patel KA, Mathur S, Upadhyay S. (2015). A comparative evaluation of bond strength of feldspathic porcelain to nickel chromium alloy, when subjected to various surface treatments: An in vitro study. J Indian Prosthodont Soc. 15:53 57.

9. Dos Santos JG, Fonseca RG, Adabo GL, dos Santos Cruz CA. (2006). Shear bond strength of metal-ceramic repair systems. J Prosthet Dent. 96:165-173.

10. Jochen DG, Caputo AA. (1977). Composite resin repair of porcelain denture teeth. J Prosthet Dent. 38:673-679.

11. Schmage P, Nergiz I, Ozcan M. (2003). Influence of various surface conditioning methods on bond strength of metal brackets to ceramic surface. J Orth Dentofacial Orthop. 123:540-546.
12. Kukiattrakoon B, Thainmasitboon K. (2007). The effect of different etching times of acidulated phosphate fluoride gel on the shear bond strength of high-leucite ceramics bonded to composite resin. J Prosthet Dent. 98:17-23.

13. Santos I, Fonseca R, Adaba €i, Cruz C. (2006). Shear bond strength of metal-ceramic repair systems. J Prosthet Dent. 96: 165-173.

14. Güler A, Yilmaz F, Ural C, Güler E. (2005). Evaluation of 24hour shear bond strength of resin composite to porcelain according to surface treatment. J Prosthod. 18: 156-160.

15. Haselton DR, Diaz-ArnoldAM, Dunne JT Jr. (2001). Shear bond strengths of 2 intraoral porcelain repair systems to porcelain or metal substrates. J Prosthet Dent. 86:526-531.

16. Pameijer CH, Louw NP. (1996). Fischer D. Repairing fractured porcelain: How surface preparation affects shear force resistance. JAm Dent Assoc. 127:203-209.

17. Chung KH, HwangYC. (1997). Bonding strengths of porcelain repair systems with various surface treatments. J Prosthet Dent. 78:267-274.

18. Chen JH, Matsumura H, Atsuta M. (1998). Effect of etchant, etching period, and silane priming on bond strength to porcelain of composite resin. Oper Dent. 23:250-257.

19. Ozcan, M. (2003). Evaluation of alternative intra-oral repair techniques for fractured ceramic-fused-to-metal restorations: review. J Oral Rehabil. 30:194-203.

20. Roeters J.J. (2000). A simple method to protect patient and environment when using sandblasting for intraoral repair. J Adhesive Dent. 2:235-238.

21. Yesil Z.D, Karaoglanoglu S, Akyil M.S. and Seven, N. (2007). Evaluation of the bond strength of different bonding agents to porcelain and metal alloy. Int J Adhes Adhes. 27: 258-262.

22. Al-Moaleem MM, Al-Sanabani FA, Al-Labani MA, Alsadidi AAF. (2013). Effects of Different Surface Treatments on Ceramo-Metalic Surfaces. International Journal of Health Sciences \& Research. 3(9): 87-96.

23. Borges GA, Sophr AM, de Goes MF, Sobrinho LC, Chan DC. (2003). Effect of etching and airborne particle abrasion on the microstructure of different dental ceramics. J Prosthet Dent. 89:479-488.

24. Panah FG, Rezai SM, Ahmadian L. (2008). The influence of ceramic surface treatments on the micro-shear bond strength of composite resin to IPS Empress 2. J Prosthodont. 17:409-414.

25. Jain S, Parkash H, Gupta S, Bhargava A. (2013). To evaluate the effect of various surface treatments on the shear bond strength of three different intraoral ceramic repair systems: an in vitro study. J Indian Prosthodont Soc. 3:315-320.

26. Proano P, Pfeiffer P, Nergiz I, Niedermeier W. (1998). Shear bond strength of repair resin using an intraoral tribochemical coating on ceramometal, ceramic, and resin surfaces. J Adhes Sci Technol. 10:1121-1135.

27. Shirani F, Kianipour A, Rahbar M. (2020). The Effect of Mechanical and Chemical Surface Preparation Methods on the Bond Strength in Repairing the Surface of Metal-Ceramic Crowns with Composite Resin: a Systematic Review and MetaAnalysis. Journal of Clinical Medicine. 15(2): 206-223.

28. Gourav R, Ariga P, Jain AR, Philip JM. (2013). Effect of four different surface treatments on shear bond strength of three porcelain repair systems: An in vitro study. J Conserv Dent. 18(3):208-212.

29. Ozcan M, Sleen MJ, Kurunmaki H, Vallittu KP. (2006). Comparison of repair methods for ceramic fused to metal crowns. J Prosthodont. 15:283-288.

30. Yadav JS, Dabas N, Bhargava A, Malhotra P, Yadav B, Sehgal M. (2019). Comparing two intraoral porcelain repair systems 
for shear bond strength in repaired cohesive and adhesive fractures, for porcelain fused to metal restorations: An in vitro study. J Indian Prosthodont Soc. 19:362-368.
This work is licensed under Creative Commons Attribution 4.0 License

To Submit Your Article Click Here: Submit Manuscript

DOI: $10.31579 / 2690-4861 / 162$
Ready to submit your research? Choose Auctores and benefit from:

* fast, convenient online submission

* rigorous peer review by experienced research in your field

* rapid publication on acceptance

* authors retain copyrights

* unique DOI for all articles

* immediate, unrestricted online access

At Auctores, research is always in progress.

Learn for more auctoresonline.org/journals/international-journal-ofclinical-case-reports-and-reviews 